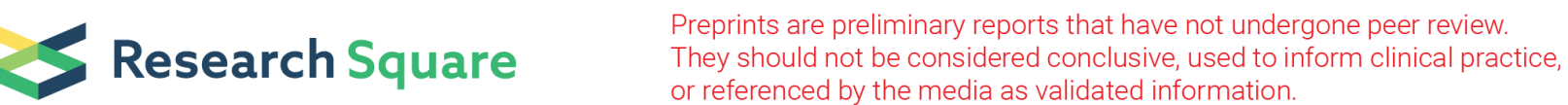

\section{A CH-Controlled Colorimetric Probe Based on Anthracene Carboximide for the Near-Infrared Detection of Cyanide}

\section{Haibing Shao}

Shanghai Institute of Technology

\section{Xi Chen}

Shanghai Institute of Technology

Tingting Zhu

Shanghai Institute of Technology

\section{Zhihua Chen}

Shanghai Institute of Technology

\section{Yan $\mathrm{Hu}$}

Shanghai Institute of Technology

\section{Hua Zhang}

Shanghai Institute of Technology

\section{Zhonghua Wang}

Shanghai Institute of Technology

Chuanxiang Liu ( $\nabla$ cxliu@sit.edu.cn )

Shanghai Institute of Technology https://orcid.org/0000-0002-4340-0667

\section{Research Article}

Keywords: Anthracene carboximide, Cyanide probe, Near-infrared, Deprotonation

Posted Date: July 7th, 2021

DOI: https://doi.org/10.21203/rs.3.rs-637177/v1

License: (c) (1) This work is licensed under a Creative Commons Attribution 4.0 International License. Read Full License 


\section{Abstract}

A novel $\mathrm{CH}$-controlled colorimetric probe based on anthracene carboximide was developed for the nearinfrared detection of cyanide. The probe was constructed by attachment of a $\mathrm{CHCN}$ binding site to anthracene carboximide fluorophore, and it showed a significant visual change from yellow-green (535 $\mathrm{nm}$ ) to deep violet $(825 \mathrm{~nm})$ with a larger redshift $(\approx 290 \mathrm{~nm})$ when interacting with cyanide. The $\mathrm{C}-\mathrm{H}$ deprotonation sensing mechanism was confirmed by ${ }^{1} \mathrm{H}$ NMR titration. Additionally, colorimetric test paper was conveniently used to detect cyanide in aqueous solutions. The near-infrared detection of cyanide by $\mathrm{CH}$-controlled probes was founded for the first time.

\section{Introduction}

Anions have excellent applications in many fields [1, 2], such as biology, chemical environment, among which cyanide play key roles in pharmaceuticals, electroplating, and metallurgy [3, 4]. However, excessive cyanide will cause serious harm to organisms and the environment. Cyanide can form stable complexes with cytochrome-c oxidase in the bloodstream of mammals, disrupting the cellular respiration process, and promoting subsequent cellular death $[5,6]$. The World Health Organization (WHO) stipulates that the concentration of cyanide ions in drinking water should not be higher than $1.9 \mu \mathrm{M}[7,8]$. Therefore, the development of an analytical method for cyanide detection is required. A lot of methods have been employed to detect cyanide, for instance, titration [9], mass spectrometry [10], Raman spectroscopy [11], potentiometry [12], chromatography [13], electrochemistry [14], fluorescence technique and colorimetric methods [15]. The colorimetric method has attracted wide attention due to its low cost, convenient operation, and

\section{Research Highlights}

1. 1. The novel near-infrared detection of cyanide by $\mathrm{CH}$-controlled was reported for the first time.

2. 2. The probe detects cyanide conveniently in aqueous solution and can be reused by TFA.

Electronic supplementary material The online version of this article ( ) contains supplementary material, which is available to authorized users.

* Chuanxiang Liu

cxliu@sit.edu.cn

School of Chemical and Environmental Engineering, Shanghai Institute of Technology, 201418 Shanghai, P. R. China

rapid response $[16,17]$. Therefore, the design of colorimetric probes is of great interest for detecting cyanide conveniently. 
The design of colorimetric probes based on the signal unit (fluorophore or chromophore) with binding sites (usually employed $\mathrm{NH}$ or $\mathrm{OH}$ ) to detect cyanide have been widely studied due to its relative acidity of $\mathrm{NH}$ or $\mathrm{OH}$ group, which can form hydrogen bonding with cyanide or induce deprotonation favoring the fluorescent and colorimetric changes [18-21]. Recently, the activated $\mathrm{CH}$ group, such as the $\mathrm{CHCN}$ group, was successfully employed as a binding site to develop a series of cyanide probes [22-26]. Especially, similar naphthalimide fluorophore containing different binding sites, such as $1 \mathrm{a}(\mathrm{NH})$ [27], 1b (OH) [28] and 1c $(\mathrm{CHCN})$ [29], have different redshift wavelengths of probes with fluoride. Probe 1c displays drastic color changes with an absorption wavelength shift of $\sim 287 \mathrm{~nm}$ (Table. 1), and the wavelength shift is more significant than that of $1 \mathrm{a}(\mathrm{NH}, 130 \mathrm{~nm})$ and $1 \mathrm{~b}(\mathrm{OH}, 112 \mathrm{~nm})$. The redshift of the probe might be attributed to the $\mathrm{CHCN}$ deprotonation, making the probe framework more rigidity, which benefits the electronic transfer. Considering the redshift property of $\mathrm{CHCN}$ group and continuing interest in developing novel cyanide sensors with near-infrared responses, we proposed the synthesis of a $\mathrm{CH}$-controlled colorimetric probe based on anthracene carboximide.

Table 1

Comparison of the similar naphthalimide fluorophore with the different binding sites (-NH, $-\mathrm{OH}$ and $-\mathrm{CH}$ group) for detection of fluoride anions.

\begin{tabular}{|c|c|c|c|c|}
\hline Probe & $\lambda_{\max }(n m)$ & \multicolumn{2}{|c|}{ Probe + F } & $\Delta \lambda(\mathrm{nm})$ \\
\hline $\begin{array}{l}\text { 1a: } \mathrm{R}=\mathrm{C}_{6} \mathrm{H}_{5} \mathrm{CO} \\
\mathrm{X}=\mathrm{NH}\end{array}$ & 360 & 490 & 130 & \\
\hline $\begin{array}{l}\text { 1b: } \mathrm{R}=\mathrm{C}_{\mathbf{4}} \mathrm{H}_{9}\left(\mathrm{CH}_{3}\right)_{2} \mathrm{Si} \\
X=0\end{array}$ & 362 & 474 & 112 & \\
\hline $\begin{array}{l}\text { 1c: } \mathrm{R}=\mathrm{C}_{5} \mathrm{H}_{4} \mathrm{~N} \\
\mathrm{X}=\mathrm{CHCN}\end{array}$ & 350 & 637 & 287 & \\
\hline
\end{tabular}

To the best of our knowledge, anthracene carboxamide-derived framework as fluorophores for $\mathrm{CN}^{-}$ sensing and the cyanide sensing featuring at near-infrared (NIR囚: $700 \sim 1000 \mathrm{~nm}$ ) region has yet to be studied [30,31]. In this work, a new $\mathrm{CH}$ controlled colorimetric probe 3 based on anthracene carboxamide was developed for the near-infrared detection of cyanide (Fig. 1). The probe was constructed by attachment of a $\mathrm{CHCN}$ binding site to anthracene carboximide fluorophore, and it could exhibit a significant visual change from yellow-green $(535 \mathrm{~nm})$ to deep violet $(825 \mathrm{~nm})$ with a huge redshift $(\approx 290$ $\mathrm{nm}$ ) when interacting with cyanide.

\section{Experimental}

\section{General information}


All solvents and reagents obtained from commercial suppliers and can be used unless further purification. Column chromatography was carried out using silica gel (200-300 mesh). The UV-visible absorption spectrum was obtained using a SHIMADZU UV-1800 spectrophotometer. Fluorescence emission spectra were measured using a Hitachi F-4600 fluorescence spectrophotometer. The ${ }^{1} \mathrm{H}$ and ${ }^{13} \mathrm{C}$ NMR spectra were operated on the Bruker AVANCE III spectrometer ( $500 \mathrm{MHz}$ for ${ }^{1} \mathrm{H}$ NMR and $125 \mathrm{MHz}$ for ${ }^{13} \mathrm{C}$ NMR), using tetramethylsilane (TMS) as internal standard. High resolution mass spectrums (HRMS) were measured on a solanX 70 FT-MS spectrometer.

\section{Synthesis of probe 3}

The synthetic route to target probe 3 is shown in Scheme 1. It was conveniently synthesized by the condensation of N-butyl-6-bromo-1,2-anthracene carboximide (1) [32] with 4-Nitrophenylacetonitrile (2) in THF, using $\mathrm{NaH}$ as a catalyst. The structures of the compounds (3) were confirmed by ${ }^{1} \mathrm{H} \mathrm{NMR},{ }^{13} \mathrm{C} \mathrm{NMR}$, HRMS. (Fig. S1-S3).

Under a $\mathrm{N}_{2}$ atmosphere, the mixture of $\mathrm{NaH}(60 \%, 95 \mathrm{mg}, 4.0 \mathrm{mmol}$ ) and 4-Nitrobenzeneacetonitrile (480 $\mathrm{mg}, 3.0 \mathrm{mmol})$ in THF $(10 \mathrm{~mL})$ was stirred at room temperature for $4 \mathrm{~min}$, followed by the addition of compound 1 ( $760 \mathrm{mg}, 2.0 \mathrm{mmol})$. The reaction was proceeded at $50^{\circ} \mathrm{C}$ for 4 hours. After completion of the reaction, the solution was cooled to rt, quenched with saturated citric acid, and extracted with saturated aq solution of $\mathrm{NaCl}$ and ethyl acetate. The organic layer was washed with $\mathrm{H}_{2} \mathrm{O}$ and dried by $\mathrm{NaSO}_{4}$, purified via column chromatography using PE-DCM (2:1) mixture as eluant to obtain compound 1 with $84 \%$ yield $(780 \mathrm{mg}, 1.68 \mathrm{mmol})$ as a yellow solid. ${ }^{1} \mathrm{H} \mathrm{NMR}\left(500 \mathrm{MHz}, \mathrm{CDCl}_{3}\right) \delta: 10.15(\mathrm{~d}, J=9.5 \mathrm{~Hz}$, $1 \mathrm{H}), 8.77(\mathrm{~d}, J=6.5 \mathrm{~Hz}, 1 \mathrm{H}), 8.45(\mathrm{~d}, J=8.0 \mathrm{~Hz}, 1 \mathrm{H}), 8.15-8.23(\mathrm{~m}, 3 \mathrm{H}), 7.83\left(\mathrm{t}, J_{1}=8.0 \mathrm{~Hz}, J_{2}=7.5 \mathrm{~Hz}\right.$, $1 \mathrm{H}), 7.77\left(\mathrm{t}, J_{1}=J_{2}=8.0 \mathrm{~Hz}, 1 \mathrm{H}\right), 7.68\left(\mathrm{t}, J_{1}=8.0 \mathrm{~Hz}, J_{2}=7.5 \mathrm{~Hz}, 1 \mathrm{H}\right), 7.49(\mathrm{~d}, J=8.5 \mathrm{~Hz}, 2 \mathrm{H}), 6.89(\mathrm{~s}, 1 \mathrm{H})$, $4.26\left(\mathrm{t}, J_{1}=J_{2}=8.0 \mathrm{~Hz}, 2 \mathrm{H}\right), 1.73-1.80(\mathrm{~m}, 2 \mathrm{H}), 1.45-1.52(\mathrm{~m}, 2 \mathrm{H}), 1.00\left(\mathrm{t}, J_{1}=J_{2}=7.5 \mathrm{~Hz}, 3 \mathrm{H}\right) .{ }^{13} \mathrm{C} \mathrm{NMR}$

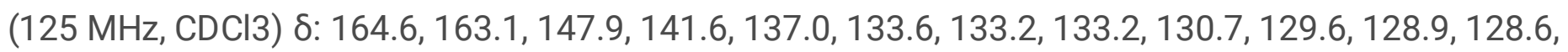
$128.4,128.3,127.7,127.4,124.7,124.3,123.8,118.5,117.9,40.8,35.9,30.2,20.5,14.2$. HRMS (ESI): $\mathrm{m} / \mathrm{z}$ calcd for $\mathrm{C}_{28} \mathrm{H}_{22} \mathrm{~N}_{3} \mathrm{O}_{4}[\mathrm{M}+\mathrm{H}]^{+}, 464.1610$;found, 464.1610 .

\section{Results And Discussion}

\section{Solvent effect}

The framework of anthracene carboximide may be sensitive to the surrounding medium. A series of the absorption curves of probe $\mathbf{3}$ in different solvents were recorded and shown in Fig. S4a, S4b. The UV absorption of probe $\mathbf{3}$ in low polarity solvents is relatively stable, and a strong absorption peak appeared at $800-825 \mathrm{~nm}$ after the addition of cyanide ion (PE, DCM, THF, etc.). However, in strong polar solvents (DMF, DMSO, MeOH, etc.), the moderate absorption peak still appeared at $800-825 \mathrm{~nm}$ in the absence of $\mathrm{CN}^{-}$, showing that the probe 3 is sensitive to the high polar solvents. A maximum UV absorbance response was observed in THF. Therefore, THF was selected as the optimum solvent to identify cyanides. 


\section{UV-vis spectra response of probe 3 to cyanide ion}

To tested the selectivity of probe 3 toward cyanide ion, a variety of anions were using, including $\mathrm{F}^{-}, \mathrm{Cl}^{\square}, \mathrm{Br}^{\square}$, $\mathrm{I}^{\square}, \mathrm{HSO}_{4}, \mathrm{H}_{2} \mathrm{PO}_{4}, \mathrm{AcO}^{\square}, \mathrm{BF}_{4}, \mathrm{NO}_{3}{ }^{\square}, \mathrm{ClO}_{4}{ }^{\square}, \mathrm{S}^{2 \rrbracket}, \mathrm{SCN}^{\square}$ (as their TBA salts) in THF. As shown in Fig.2a, two absorption peaks at $535 \mathrm{~nm}$ and $825 \mathrm{~nm}$ appeared when the $\mathrm{CN}^{\square}$ solution (TBACN) was added. Except for $\mathrm{H}_{2} \mathrm{PO}_{4}{ }^{\square}, \mathrm{AcO}^{\square}$ and $\mathrm{F}^{\square}$, the interference of other anions was almost negligible, indicating the excellent selectivity of probe $\mathbf{3}$ for strong base anions. We propose that the reason of the probe $\mathbf{3}$ results from its strong acidity of $\mathrm{CHCN}$ group, which can be enhanced by the remote electron-withdrawing group (dicarbonyl group and nitro group). Moreover, the UV-vis spectra titration experiment of probe $\mathbf{3}$ with $\mathrm{CN}^{\square}$ $(20 \mu \mathrm{M})$ were conducted in THF (Fig.2b). These new absorption peaks at $535 \mathrm{~nm}$ and $825 \mathrm{~nm}$ were emerged and enhanced gradually with the addition of $\mathrm{CN}^{\square}$, concomitantly, the color of the solution changed from yellow-green to deep violet. An excellent near-linear correlation between the absorbance at $825 \mathrm{~nm}$ and cyanide ion concentration in THF solution can be observed in a range of $0-80 \mu \mathrm{M}$, meanwhile probe 3 of the detection limit (LOD) was calculated to be $0.61 \mu \mathrm{M}$ by applying equation LOD = $3 \delta / \mathrm{S}$ (Fig. S5). Table. S1 shows probe $\mathbf{3}$ is sensitive to cyanide. The result provides that probe $\mathbf{3}$ is expected to be used as a quantitative detection of $\mathrm{CN}^{\natural}$. Competitive experiments using other potentially interfering ions were also recorded. Figure $2 \mathrm{c}$ shows that, except for $\mathrm{H}_{2} \mathrm{PO}_{4}, \mathrm{AcO}^{\square}$ and $\mathrm{F}^{\square}$, the other anions caused negligible interference in THF. In addition, the Job curves disclose the 1:1 binding stoichiometry of probe 3 interact with $\mathrm{CN}^{\square}$ (Fig. S6).

Figure 2 (a) UV-vis absorbance spectra change of probe $3(20 \mu \mathrm{M})$ in the presence of various TBA salt analytes (ca. 4.0 equiv.) in THF solution. Inset: Photograph of naked-eye color change of probe $\mathbf{3}$ with 4.0 equiv. anions (from left to right: probe 3 only, $\mathrm{CN}^{-}, \mathrm{F}^{\square}, \mathrm{Cl}^{\square}, \mathrm{Br}^{\square}, \mathrm{I}^{\square}, \mathrm{HSO}_{4}{ }^{\square}, \mathrm{H}_{2} \mathrm{PO}_{4}, \mathrm{AcO}^{\square}, \mathrm{BF}_{4}^{\square}, \mathrm{NO}_{3}{ }^{\square}, \mathrm{ClO}_{4}{ }^{\square}, \mathrm{S}^{2 \rrbracket}$,

$\left.\mathrm{SCN}^{\square}\right)$. (b) UV-vis titration spectra change of probe $3(20 \mu \mathrm{M})$ containing different concentrations of TBACN in THF solution. Inset: Plot of absorption intensity vs concentration of $\mathrm{CN}^{\square}$ at $\lambda=825 \mathrm{~nm}$. (c). Absorption intensity interference experiment of probe 3 ; black bar: probe 3 with specified anion $(20 \mu \mathrm{M})$, red bar: probe 3 with specified anion + cyanide ion $(20 \mu \mathrm{M})$. (From left to right: $\mathrm{CN}^{\square}, \mathrm{F}^{\square}, \mathrm{Cl}^{\square}, \mathrm{Br}^{\square}, \mathrm{I}^{\square}, \mathrm{HSO}_{4}^{\square}$, $\mathrm{H}_{2} \mathrm{PO}_{4}^{\square}, \mathrm{AcO}^{\square}, \mathrm{BF}_{4}^{\square}, \mathrm{NO}_{3}{ }^{\square}, \mathrm{ClO}_{4}^{\square}, \mathrm{S}^{2 \rrbracket}, \mathrm{SCN}^{\square}$ ).

\section{Fluorescence spectra response of probe 3 to cyanide ion}

The fluorescence behaviour of probe $\mathbf{3}(20 \mu \mathrm{M})$ were recorded in THF solution. Probe $\mathbf{3}$ exhibited two strong emission peaks at $480 \mathrm{~nm}$ and $520 \mathrm{~nm}$ initially. After the cyanide ions were added, the fluorescence intensity reduced rapidly. Except for $\mathrm{H}_{2} \mathrm{PO}_{4}^{-}, \mathrm{AcO}^{\square}$ and $\mathrm{F}^{\square}$, other anions produced fluorescence changes are almost ignorable (Fig. 3a). This fluorescence quenching was attributed primarily to the deprotonation of the $\mathrm{CH}$ group when probe 3 interacted with the strong basic anions. Moreover, fluorescence titration of probe 3 with increasing concentration of $\mathrm{CN}^{\square}$ was also examined in Fig. 3b. The peaks at 480 and $520 \mathrm{~nm}$ decreased gradually around 4000 -fold with the increase of $\mathrm{CN}^{\square}$ content from 0 to $80 \mu \mathrm{M}$. Obviously, other competitor anions, in particular fluoride, did not produce significant 
fluorescence color changes, whereas on $\mathrm{CN}^{\square}$ addition at the equal concentration could almost quench the fluorescence completely. ( $80 \mu \mathrm{M})$ (Fig. 3c). These phenomena disclosed that probe 3 reveals excellent selectivity for sensing of $\mathrm{CN}^{\square}$.

Figure 4 (a) Fluorescence emission spectra change of probe $3(20 \mu \mathrm{M})$ in the presence of various TBA salt analytes (ca. 4.0 equiv.) in THF solution. Inset: Fluorescence color change of probe 3 with 4.0 equiv. anions (from left to right: probe 3 only, $\mathrm{CN}^{-}, \mathrm{F}^{\square}, \mathrm{Cl}^{\square}, \mathrm{Br}^{\square}, \mathrm{I}^{\square}, \mathrm{HSO}_{4}{ }^{\square}, \mathrm{H}_{2} \mathrm{PO}_{4}{ }^{\square}, \mathrm{ACO}^{\square}, \mathrm{BF}_{4}{ }^{\square}, \mathrm{NO}_{3}{ }^{\square}, \mathrm{ClO}_{4}{ }^{\square}, \mathrm{S}^{2 \rrbracket}, \mathrm{SCN}^{\square}$ ). (b) Fluorescence titration spectra change of probe $3(20 \mu \mathrm{M})$ containing different concentrations of TBACN in THF solution. Inset: Plot of fluorescence intensity vs concentration of $\mathrm{CN}^{\square}$ at $\lambda=480 \mathrm{~nm}$. (c). Fluorescence intensity interference experiment of probe 3 ; black bar: probe 3 with specified anion (20 $\mu \mathrm{M})$, red bar: probe 3 with specified anion + cyanide ion $(20 \mu \mathrm{M})$. (from left to right: $\mathrm{CN}^{\square}, \mathrm{F}^{\square}, \mathrm{Cl}^{\square}, \mathrm{Br}^{\square}, \mathrm{I}^{\square}$, $\left.\mathrm{HSO}_{4}{ }^{\square}, \mathrm{H}_{2} \mathrm{PO}_{4}, \mathrm{ACO}^{\square}, \mathrm{BF}_{4}, \mathrm{NO}_{3}{ }^{\square}, \mathrm{ClO}_{4}{ }^{\square}, \mathrm{S}^{2 区}, \mathrm{SCN}^{\square}\right)$.

\section{Reversibility and reusability responses of probe 3 to cyanide ion and application}

Only a few reported chemical sensors could operate with optical reversibility and reusability, thus the probe applications are limited in many fields $[33,34]$. To test the reversibility of probe 3 , the UV-vis spectrum study of [ $3+\mathrm{CN}]$ complex to trifluoroacetic acid (TFA) was performed. With the increase of TFA content, these absorption bands at 535 and $825 \mathrm{~nm}$ gradually rise. When TFA increased to 8.0 equiv., These absorption peaks kept stable and reached the saturation state after addition of 8.0 equivalents of TFA. Meanwhile the visible color has returned to the initial state of probe $\mathbf{3}$ from purple to yellow-green, indicating that the deprotonated $\mathrm{CH}$ group could be acidic. Cyclic titration experiments were performed by the addition of TFA and $\mathrm{CN}^{\square}$ repeatedly. The naked-eye visible color changed from yellow-green to purple and then back to initial color, indicating that the whole deprotonation process is reversible, and probe 3 could operate with the advantage of the reusability. Fluorescence alternate titrations of $\left[3+\mathrm{CN}^{[}\right]$complex to TFA were also carried out. The emission peaks go up at $480 \mathrm{~nm}$ and $520 \mathrm{~nm}$ as the concentration of TFA increase, and return to the original state of probe 3 . Similarly, the reversible fluorescence responses were studied by alternate titration experiments. Fluorescence state turned from ON to OFF and then return to $\mathrm{ON}$. It further demonstrates that probe $\mathbf{3}$ will be deprotonated by a strong basic anion followed by protonation in an acidic environment to achieve the advantage of optical reversibility and reusability. (Fig. 4a-4f).

To study the applicability of probe $\mathbf{3}$ in daily life, test strip experiments were conducted. The test papers were immersed in the probe 3 solution ( $1 \mathrm{mM}, \mathrm{THF}$ ) for 2 hours and then dried naturally. Then the probeloaded test strips were dipped into TBACN solutions of different concentrations. The test papers showed obvious visible color change from yellow to purple as the CN'concentration increased (Fig. S7).

Interestingly, the test paper can be reused by TFA (Fig. 5). Similarly, the silica gel plates showed that the fluorescence intensity changed with the concentration of cyanide ions under a UV lamp at $365 \mathrm{~nm}$ after 
soaking in the probe solution for 2 hours (Fig. S8), fluorescence intensity returned to its original state

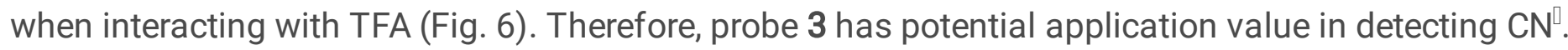

\section{${ }^{1} \mathrm{H}$ NMR titration experiments}

To better understand the deprotonation of the probe $3,{ }^{1} \mathrm{H}$ NMR titration experiments were carried out in $\mathrm{CDCl}_{3}$ solution (Fig. 7). As the content of $\mathrm{CN}^{-}$increased, the characteristic $\mathrm{H}_{\mathrm{f}}$ band at $6.89 \mathrm{ppm}$ disappeared gradually and a new signal band appeared concomitantly at $6.54 \mathrm{ppm}$. After addition of 4.0 equiv. $\mathrm{CN}^{\square}$, the $\mathrm{C}-\mathrm{H}$ band at $6.89 \mathrm{ppm}$ diminished completely meanwhile other peaks range from 6.0 to $10.5 \mathrm{ppm}$ move to some degrees. Thus, the deprotonation mechanism of probe $\mathbf{3}$ with cyanide ion had been finally confirmed.

\section{Conclusion}

In summary, a novel colorimetric and fluorescent probe based on anthracene carboximide by $\mathrm{CH}$ controlled was designed. The near-infrared detection of cyanide by $\mathrm{CH}$-controlled probe was reported for the first time. Experiments showed that the probe with a huge UV absorbance redshift of $290 \mathrm{~nm}$ and responded at $825 \mathrm{~nm}$ for detection $\mathrm{CN}^{-}$in THF solutions. Probe 3 also displayed excellent performance in selectivity, anti-interference, and reversibility. The mechanism of the $\mathrm{C}-\mathrm{H}$ group deprotonation was confirmed according to ${ }^{1} \mathrm{H}$ NMR titration. Moreover, the practical applicability of probe $\mathbf{3}$ for detecting cyanide ion has been studied by a series of experiments. Importantly, this work offers a novel strategy for designing large redshift cyanide ion probes based on activated $\mathrm{CH}$ groups.

\section{Declarations}

Acknowledgements

We thank the Natural Science Foundation of Shanghai (No. 17ZR1429900) and the Opening Fund of Shanghai Key Laboratory of Chemical Biology for financial support.

Funding

The Natural Science Foundation of Shanghai (No. 17ZR1429900) and the Opening Fund of Shanghai Key Laboratory of Chemical Biology.

Author Contributions

All authors contributed to the study conception and design. Haibing Shao carried out the experiments, Xi Chen, Tingting Zhu, Zhihua Chen, Yan Hu and Hua Zhang conducted the data analyses, Zhonghua Wang and Chuanxiang Liu wrote and edited the paper.

Data Availability 
Not applicable.

Code Availability

Not applicable.

\section{Author information}

Affiliations

School of Chemical and Environmental Engineering, Shanghai Institute of Technology, 201418 Shanghai, P. R. China

Haibing Shao, Xi Chen, Tingting Zhu, Zhihua Chen, Yan Hu, Hua Zhang, Zhonghua Wang * and Chuanxiang Liu *

Corresponding author

Correspondence to Chuanxiang Liu.

\section{Author Declarations}

Consent to Participate

Not Applicable.

Consent for Publication

Not Applicable.

Conflicts of interest

There are no conflicts of interest to declare.

Ethics Approval

Not Applicable.

\section{References}

1. Chen D, Letcher RJ, Gauthier LT, Chu S, McCrindle R, Potter D (2011) Novel Methoxylated Polybrominated Diphenoxybenzene Congeners and Possible Sources in Herring Gull Eggs from the 
Laurentian Great Lakes of North America. Environ Sci Technol 45:9523-9530

2. Goldwasser P, Manjappa NG, Luhrs CA, Barth RH (2011) Pseudohypobicarbonatemia Caused by an Endogenous Assay Interferent: A New Entity. Am J Kidney Dis 58:617-620

3. Peng L, Wang M, Zhang G, Zhang D, Zhu D (2009) A Fluorescence Turn-on Detection of Cyanide in Aqueous Solution Based on the Aggregation-Induced Emission. Org Lett 11:1943-1946

4. Lebeda FJ, Deshpande SS (1990) Potentiometric Measurements of Hydrogen and Cyanide Ions in Buffered Media. Anal Biochem 187:302-309

5. Dash RR, Gaur A, Balomajumder C (2009) Cyanide in industrial wastewaters and its removal: A review on biotreatment. J Hazard Mater 163:1-11

6. Zeng JB, Cao YY, Chen JJ, Wang XD, Yu JF, Yu BB, Yan ZF, Chen X (2014) Au@Ag core/shell nanoparticles as colorimetric probes forcyanide sensing. Nanoscale 6:9939-9943

7. Peng MJ, Guo Y, Yang XF, Suzenet F, Li J, Li CW, Duan YW (2014) Coumarin-hemicyanine conjugates as novel reaction-based sensors for cyanide detection: convenient synthesis and ICT mechanism. RSC Adv 4:19077-19085

8. Wang L, Zhu L, Cao D (2015) A colorimetric probe based on diketopyrrolopyrrole and tert-butyl cyanoacetate for cyanide detection. New J Chem 39:7211-7218

9. Konidena RK, Thomas KRJ (2014) Selective naked-eye cyanide detection in aqueous media using a carbazole-derived fluorescent dye. RSC Adv 4:22902-22910

10. Wang F, Wang L, Chen X, Yoon J (2014) Recent progress in the development of fluorometric and colorimetric chemosensors for detection of cyanide ions. Chem Soc Rev 43:4312-4324

11. Suzuki T, Hioki A, Kurahashi M (2003) Development of a method for estimating an accurate equivalence point in nickel titration of cyanide ions. Anal Chim Acta 476:159-165

12. Shan D, Mousty C, Cosnier S (2004) Subnanomolar Cyanide Detection at Polyphenol Oxidase/Clay Biosensors. Anal Chem 76:178-183

13. Isaad J, Achari AE (2011) Colorimetric sensing of cyanide anions in aqueous media based on functional surface modification of natural cellulose materials. Tetrahedron 67:4939-4947

14. Safavi A, Maleki N, Shahbaazi HR (2004) Indirect determination of cyanide ion and hydrogen cyanide by adsorptive stripping voltammetry at a mercury electrode. Anal Chim Acta 503:213-221

15. Zhang Y, Yu D, Feng G (2004) Colorimetric and near infrared fluorescent detection of cyanide by a new phenanthroimidazole-indolium conjugated probe. RSC Adv 4:14752-14757

16. Gao T, Yang S, Cao X, Dong J, Zhao N, Ge P, Zeng W, Cheng Z (2017) Smart Self-Assembled Organic Nanoprobe for Protein-Specific Detection: Design, Synthesis, Application, and Mechanism Studies. Anal Chem 89:10085-10093

17. Hua B, Shao L, Yu G, Huang F (2016) Fluorescence indicator displacement detection based on pillar [5] arene-assisted dye Deprotonation. Chem Commun 52:10016-10019

18. Sessler JL, Cai J, Gong HY, Yang X, Arambula JF, Hay BP (2010) A Pyrrolyl-Based Triazolophane: A Macrocyclic Receptor With $\mathrm{CH}$ and NH Donor Groups That Exhibits a Preference for Pyrophosphate 
Anions. J Am Chem Soc 132:14058-14060

19. Jo J, Olasz A, Chen CH, Lee D (2013) Interdigitated Hydrogen Bonds: Electrophile Activation for Covalent Capture and Fluorescence Turn-On Detection of Cyanide. J Am Chem Soc 135:3620-3632

20. Yang Z, Zhang Z, Meanwell NA, Kadow JF, Wang T (2002) A Strategy for the Synthesis of Aryl aKetoamides Based upon the Acylation of Anions Derived from Cyanomethylamines Followed by Oxidative Cleavage. Org Lett 4:1103-1105

21. Hunger M (1996) Multinuclear solid-state NMR studies of acidic and non-acidic hydroxyl protons in zeolites. Solid State Nucl Magn Reson 6:1-29

22. Zhu T, Li Z, Fu C, Chen L, Chen X, Gao C, Zhang S, Liu C (2020) Development of an anthraquinonebased cyanide colorimetric sensor with activated $\mathrm{C}-\mathrm{H}$ group: Large absorption red shift and application in food and water samples. Tetrahedron 76:131479

23. Li Z, Rao C, Chen L, Fu C, Zhu T, Chen X, Liu C (2019) Addition of a-Cyanomethylpyridine to Naphthalimide via Trifluoromethyl-Directed CH Functionalization: Cyanide Sensing in Aqueous Media. J Org Chem 84:7518-7522

24. Chen Y, Hu X, Rao C, Li Z, Chen L, Fu C, Liu C (2018) A reusable cyanide sensor via activation of C-H group: trifluoromethylcarbinol -directed meta-C-H cyanomethylation of naphthalimide. Analyst 143:4655-4661

25. Zhang C, Ji K, Wang X, Wu H, Liu C (2015) A reversible and selective chemosensor based on intramolecular $\mathrm{NH} \cdots \mathrm{NH}_{2}$ hydrogen bonding for cyanide and $\mathrm{pH}$ detection. Chem Commun 51:81738176

26. Zhou M, Chen J, Liu C, Fu H, Zheng N, Zhang C, Chen Y, Cheng J (2014) Anion binding modes in cistrans-isomers of a binding site-fluorophore- $\pi$-extended system. Chem Commun 50:14748-14751

27. Liu B, Tian H, Yu (2005) A ratiometric fluorescent chemosensor for fluoride ions based on a proton transfer signaling mechanism. J Mater Chem 15:2681-2686

28. Ren J, Wu Z, Zhou Y, Li Y,.Xu Z (2011) Colorimetric fluoride sensor based on 1,8-naphthalimide derivatives. Dyes Pigm 91:442-445

29. Chen J, Liu C, Zhang J, Ding W, Zhou M, Wu F (2013) A novel chemodosimeter for fluoride ions based on deprotonation of the $\mathrm{C}-\mathrm{H}$ group followed by an autoxidative decyanation process. Chem Commun 49:10814-10816

30. Yuan L, Lin W, Zheng K, He L, Huang W (2013) Far-red to near infrared analyte-responsive fluorescent probes based on organic fluorophore platforms for fluorescence imaging. Chem Soc Rev 42:622661

31. Shi Z, Han X, Hu W, Bai H, Peng B, Ji L, Fan Q, Li L, Huang W (2020) Bioapplications of small molecule Aza-BODIPY: from rational structural design to in vivo investigations. Chem Soc Rev 49:7533-7567

32. Gao Z, Han B, Chen K, Sun J, Hou X (2017) A novel single-fluorophore-based ratiometric fluorescent probe for direct detection of isocyanates in air. Chem Commun 53:6231-6234 
33. Xie Y, Ding Y, Li X, Wang C, Hill JP, Ariga K, Zhang W, Zhu W (2012) Selective, sensitive and reversible "turn-on" fluorescent cyanide probes based on 2,2'-dipyridylaminoanthracene- $\mathrm{Cu}^{2+}$ ensembles. Chem Commun 48:11513-11515

34. Singh G, Kaur A, Sharma M, Bhalla V, Singh D, Arora S, Kumar M (2020) Reversible detection of hypochlorite using the deprotonation -protonation strategy: a search for new building blocks. Mater Adv 1:1347-1353

\section{Table}

Table. 1 Comparison of the similar naphthalimide fluorophore with the different binding sites $(-\mathrm{NH},-\mathrm{OH}$ and - $\mathrm{CH}$ group) for detection of fluoride anions.

\begin{tabular}{|c|c|c|c|c|}
\hline \multirow[t]{4}{*}{ Probe } & \multicolumn{2}{|l|}{$\lambda_{\max }(\mathrm{nm})$} & Probe + F- & $\Delta \lambda(\mathrm{nm})$ \\
\hline & 1a: $\mathrm{R}=\mathrm{C}_{6} \mathrm{H}_{5} \mathrm{CO}$ & \multirow[t]{2}{*}{360} & \multirow[t]{2}{*}{490} & \multirow[t]{2}{*}{130} \\
\hline & $\mathrm{X}=\mathrm{NH}$ & & & \\
\hline & $1 \mathrm{~b}: \mathrm{R}=\mathrm{C}_{4} \mathrm{H}_{9}\left(\mathrm{CH}_{3}\right)_{2} \mathrm{Si}$ & 362 & 474 & 112 \\
\hline & $X=0$ & & & \\
\hline & 1c: $\mathrm{R}=\mathrm{C}_{5} \mathrm{H}_{4} \mathrm{~N}$ & 350 & 637 & 287 \\
\hline & $\mathrm{X}=\mathrm{CHCN}$ & & & \\
\hline
\end{tabular}

\section{Figures}

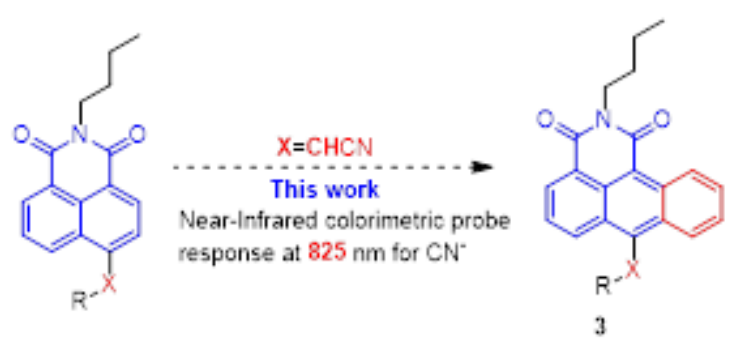

Figure 1

The development of near-infrared colorimetric probe 3 

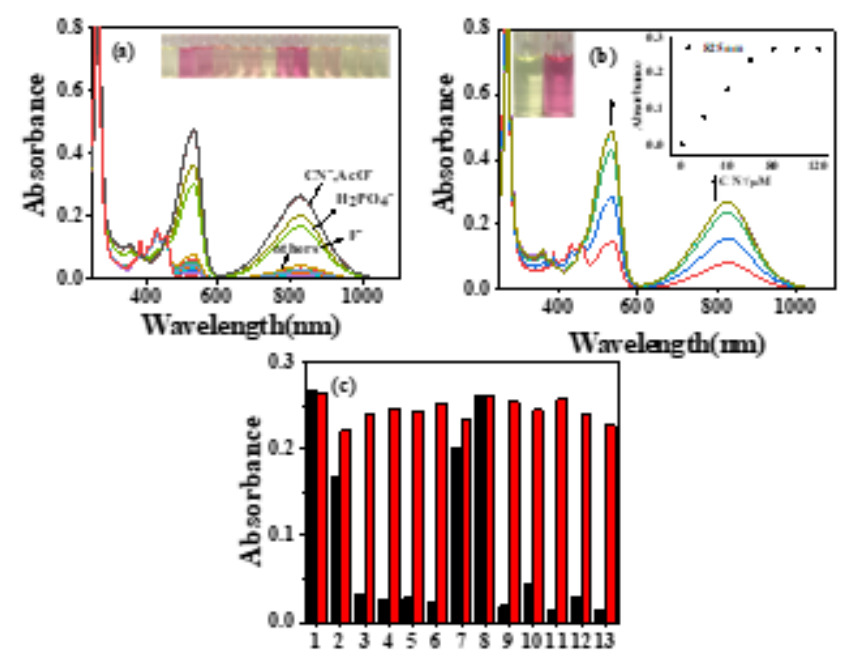

Figure 2

(a) UV-vis absorbance spectra change of probe $3(20 \mu \mathrm{M})$ in the presence of various TBA salt analytes (ca. 4.0 equiv.) in THF solution. Inset: Photograph of naked-eye color change of probe 3 with 4.0 equiv.

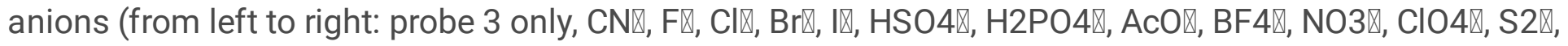
SCN区). (b) UV-vis titration spectra change of probe $3(20 \mu \mathrm{M})$ containing different concentrations of

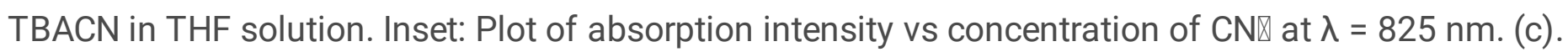
Absorption intensity interference experiment of probe 3; black bar: probe 3 with specified anion $(20 \mu \mathrm{M})$,

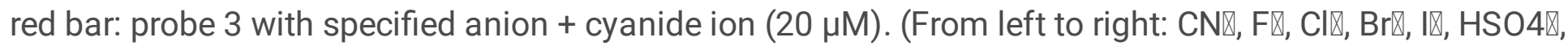

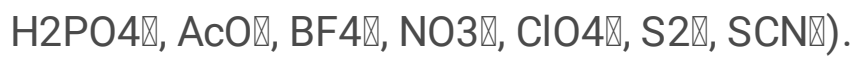
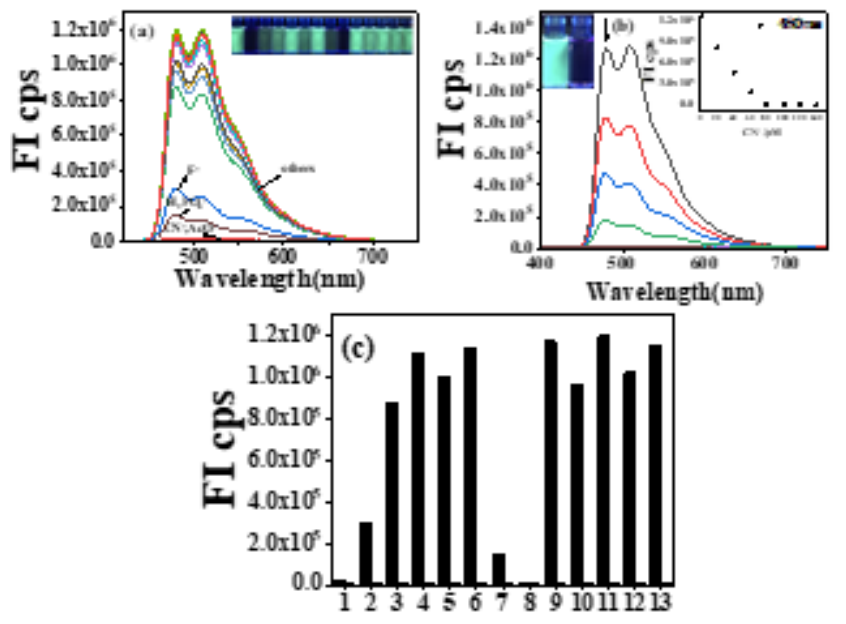

\section{Figure 3}

(a) Fluorescence emission spectra change of probe $3(20 \mu \mathrm{M})$ in the presence of various TBA salt analytes (ca. 4.0 equiv.) in THF solution. Inset: Fluorescence color change of probe 3 with 4.0 equiv.

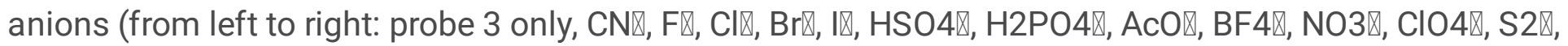
$\mathrm{SCN})$ ). (b) Fluorescence titration spectra change of probe $3(20 \mu \mathrm{M})$ containing different concentrations

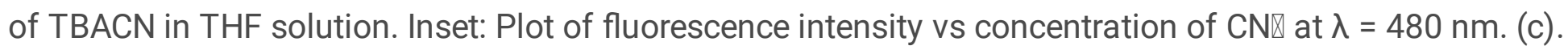
Fluorescence intensity interference experiment of probe 3; black bar: probe 3 with specified anion (20 


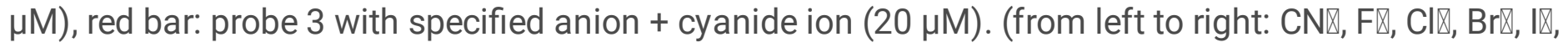

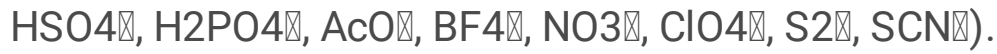
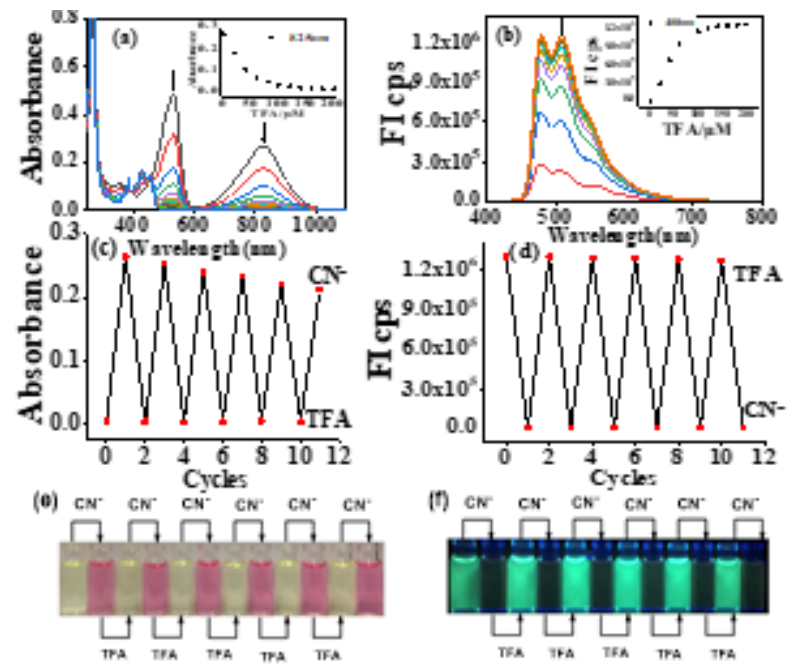

\section{Figure 4}

(a) UV-vis absorbance spectra change of [3+CN囚] complex $(20 \mu \mathrm{M})$ in the presence of TFA. Inset: Plot of absorption intensity vs concentration of TFA at $\lambda=825 \mathrm{~nm}$. (b) Fluorescence emission spectra change of [3+CN囚] complex $(20 \mu \mathrm{M})$ in the presence of TFA. Inset: Plot of fluorescence intensity vs concentration of TFA at $\lambda=480 \mathrm{~nm}$. (c) Absorption intensity of probe 3 interact with CN囚 and TFA alternately. (d) Fluorescence intensity of probe 3 interact with CN⿴ and TFA alternately. (e) Visible color change of probe

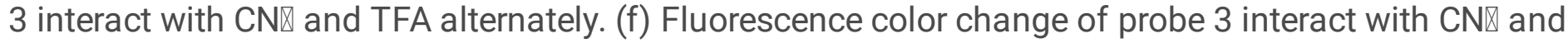
TFA alternately.

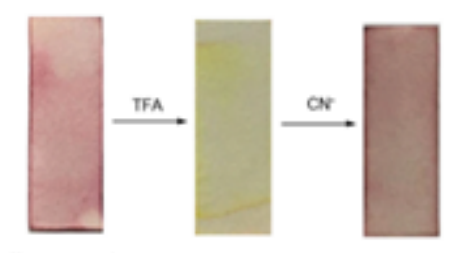

Test posere $+\mathrm{CN}$

\section{Figure 5}

Visual color changes with addition CN囚and TFA.

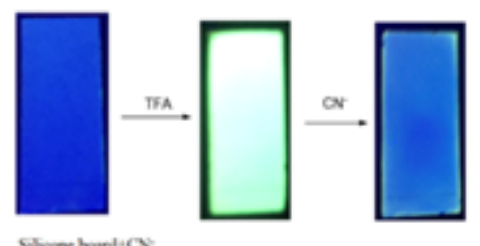

Figure 6

Visual fluorescence changes with addition CNZ and TFA under UV 


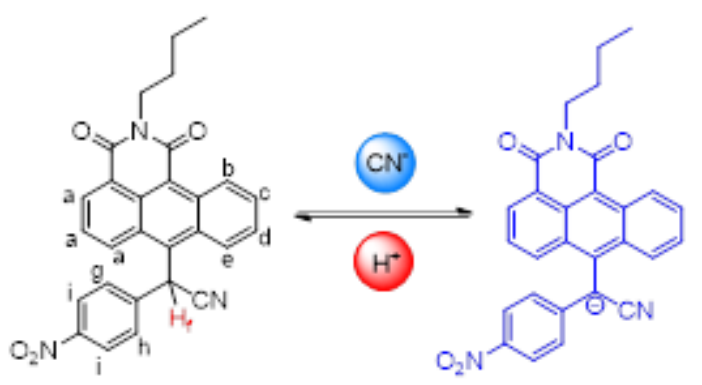

probe 3

deprotonation of probe 3

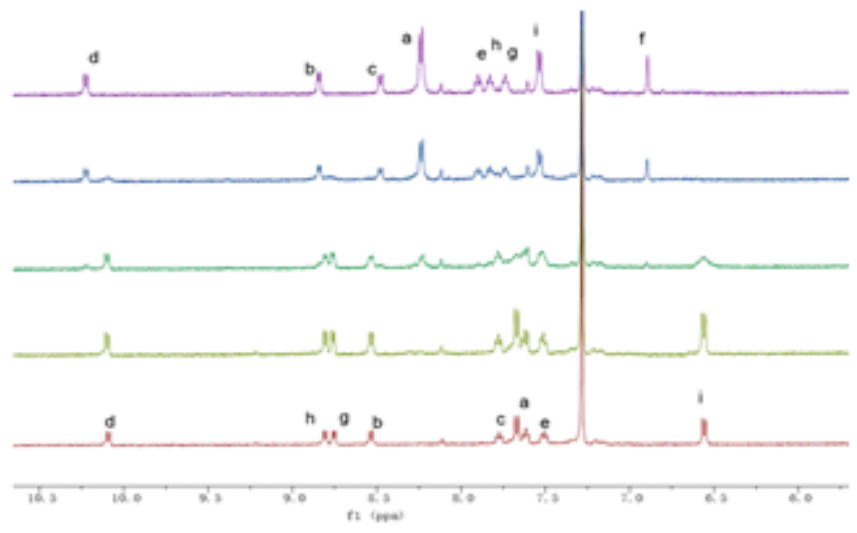

Figure 7

1H-NMR titration spectra of probe $3(30 \mathrm{mM})$ in $\mathrm{CDCl} 3$ solution after addition of various equivalents TBACN. From top to bottom: Probe 3, 1.0, 2.0, 3.0, 4.0 equiv.

\section{Supplementary Files}

This is a list of supplementary files associated with this preprint. Click to download.

- Scheme01.png 